\title{
Neonatal Surgery: Demand and Survival Both are on Increase- an Experience of Seventeen Years in Dhaka Medical College Hospital, Bangladesh
}

\author{
Hanif $\mathrm{A}^{1}$, Hasina $\mathrm{K}^{2}$, Rouf $\mathrm{MA}^{3}$, Islam $\mathrm{KMS}^{4}$, Ferdous $\mathrm{NS}^{4}$, Khan $\mathrm{JG}^{1}$, Huq $\mathrm{A}^{4}$ \\ ${ }^{I}$ Department of Neonatal Surgery, Dhaka Medical College and Hospital, Dhaka, Bangladesh; \\ ${ }^{2}$ Department of Paediatric Surgical Oncology, Dhaka Medical College and Hospital, Dhaka, \\ Bangladesh; ${ }^{3}$ Department of Surgery, North Bengal Medical College and Hospital, Sirajganj, \\ Bangladesh; ${ }^{4}$ Department of Paediatric Surgery, Dhaka Medical College and Hospital, Dhaka, \\ Bangladesh
}

\begin{abstract}
Background: In order to achieve the Sustainable Development Goal (SDG) 3 target of reduction in under-five mortality below 25 per thousand live births by the year of 2030, major reductions are going to be required in neonatal mortality. Congenital anomalies have become the fourth cause of neonatal deaths and most of these are curable. The largest public hospital of Bangladesh is serving the poor and lower middle class people where surgery and medical facilities are mostly free of cost.

Objective: This study was done to assess the types of neonatal surgical patients admitted in this hospital and their management outcome with limited facilities and explore new ideas and information and the ways to improve the scenario to contribute in achieving the SDG 3.

Methods: This was a descriptive study with retrospective record review of all admitted neonates done over a period of 17 years from July 2001 to June 2018 and carried out in the Department of Paediatric Surgery. A total of 2492 neonates were admitted during this period and it was the $16.16 \%$ of total number of 15414 paediatric surgical admission upto 12 years of age. Data were collected from hospital records and analysed retrospectively. Detail history of each patient was collected and recorded in a pre-designed, semi-structured questionnaire. Statistical analyses were done by SPSS version 22.
\end{abstract}

Results: Out of these 2492 neonates, 1932 (77.53\%) were admitted for Neonatal Intestinal Obstruction (NIO) and intestinal atresia $246(09.87 \%)$, omphalocele $163(06.54 \%)$, meconium ileus $154(06.18 \%)$, volvulous neonatoram $125(05.02 \%)$, septicemia $114(04.57 \%)$, posterior urethral valve $78(03.13 \%)$, gastroschisis $75(03.01 \%)$, abscess $57(02.29 \%)$, congenital Diaphragmatic Hernia 54 (02.17\%), ectopia vesicae $50(02.01 \%)$, infantile pyloric stenosis $42(01.68 \%)$, tracheo-oesophageal fistula $24(0.96 \%)$, prune belly syndrome $8(0.32 \%)$, neonatal injury $5(0.20 \%)$, conjoint twin $4(0.16 \%)$. The most common cause of NIO was anorectal malformation (ARM) 806 (32.34\%). And / of them $516(64.02 \%)$ patients had high variety and 290 (35.98\%) patients had low variety ARM. Next was Hirschsprungs disease and 487 (19.54\%) neonates presented with this. One hundred and forteen $(4.57 \%)$ patients presented with septicemia and 246 $(9.87 \%)$ presented with intestinal atresia, $154(6.18 \%)$ neonates had meconium ileus and $125(5.02 \%)$ patients presented with volvulus neonatorum. Total $1791(71.86 \%)$ patients were managed surgically. Most of the surgerical procedures were pelvic colostomy $541(21.71 \%)$, transverse colostomy and biopsies $376(15.09 \%)$, resection and anastomosis $261(10.47 \%)$, anoplasty $239(9.59 \%)$, primary repair $135(5.42 \%)$ and ileostomy $104(4.17 \%)$. Out of 2492 patients, 351 died, so mortality rate was $14.09 \%$, before surgery $127(5.10 \%)$ and after surgery was $224(14.85 \%)$.

Conclusion: Paediatric surgeons by their skills and teamwork greatly improved the neonatal surgical service and contributing significantly in reducing infant mortality rate to achieve SDG 3. But to improve further, neonatal intensive care unit (NICU) and other support systems are essential as well as support from UNICEF and World Health Organization (WHO) to include paediatric surgery and surgeons in their activities especially in developing countries. Due to socio-political and economic reasons of the developing countries the roll of paediatric surgeons are multidimensional.

Keywords: Neonatal surgery, Neonatal intestinal obstruction, Anorectal malformation, Sustainable development goal

\section{Introduction}

The neonatal period is the most vulnerable time for a child. Over one third of the global 10.8 million deaths of children under age 5 in the year

*Correspondence: Dr. Abdul Hanif (Tablu), Department of Paediatric Surgery, Dhaka Medical College and Hospital, Dhaka, Bangladesh; e-mail: ahaniftablu@hotmail.com; ORCID: 0000-0002-0466-9858
2000 occurred in the neonatal period. ${ }^{1}$ Globally, 2.5 million children died in the first month of life in 2017 alone - approximately 7,000 neonatal deaths every day - most of which occurred in the first week, with about 1 million dying on the first day and close to 1 million dying within the next six days. ${ }^{2}$ Declines in neonatal mortality over the 
last three decades have been slower than declines in post neonatal or early child ( 1 to 5 years) mortality. In order to achieve the Sustainable Development Goal (SDG) 3 target of reduction in under-five mortality below 25 per thousand livebirths by the year of 2030, major reductions are going to be required in neonatal mortality. ${ }^{3}$

Congenital anomalies have become the 4th cause of neonatal death and most of these are curable. ${ }^{4}$ Among maternal and fetal risk factors; parental consanguinity, maternal under nutrition and obesity, positive history of an anomaly in family, low birth weight and prematurity were significantly associated with higher frequency of congenital anomalies. Birth defects are a diverse group of disorders of prenatal origin that can be caused by single gene defect, chromosomal disorders, multifactorial inheritance, environmental teratogens and micronutrients deficiencies. ${ }^{5,6}$

Population of Bangladesh is approximately 163.05 million and about 20.628 million people live in Dhaka. ${ }^{7}$ The largest public hospital in Bangladesh is serving these poor and lower middle class people where surgery and medical facilities are mostly free of cost. The congenital anomalies treated in this hospital are anorectal malformation (ARM), Hirschsprung's disease, gastroschisis, omphalocele, intestinal atresia, meconium ileus, volvulous neonatoram, septicemia, posterior urethral valve, abscess, infantile pyloric stenosis, prune belly syndrome, neonatal injury, congenital diaphragmatic hernia, ectopia vesicae, oesophageal atresia, tracheooesophageal fistula, conjoint twin,etc. NIO is the most common form of neonatal emergencies in neonatal surgical patients. It is caused by a group of congenital anomalies and some other acquired conditions. $^{8}$ Neonatal surgeries require surgical management by pediatric surgeons in medical centers with facilities for pediatric anesthesia, radiology and the specialized nursing care for successful survival. 9 Maternal polyhydramnios, dilated fluid filled loops of gut at maternal ultrasonography and family history of cystic fibrosis or Hirschsprung disease are the antenatal diagnostic tool for NIO. It is an urgent condition that requires immediate involvement of a team of pediatric surgeon and neonatologist for perioperative management. Fluid loss, electrolyte imbalance, metabolic acidosis, hypoglycemia, hypothermia, respiratory distress and sepsis lead to high morbidity and mortality due to intestinal obstruction. ${ }^{10}$ Among urological cases, hydronephrosis may result from obstruction or reflux of urine which needs careful evaluation. The most common cause of fetal hydronephrosis is ureteropelvic junction (UPJ) obstruction. ${ }^{11}$

In the developed countries, intrauterine diagnosis, fetal intervention, planned delivery, better paediatric anaesthetic support, improved neonatal intensive care, ventilator support and prompt surgical management of relatively clinically stable neonates are possible. ${ }^{12-14}$ These were not so in this country where a majority of surgical neonates present very late. ${ }^{15}$ Late presentation is another major challenge facing the delivery of neonatal surgical services to children in Bangladesh. Many of these neonates are brought to hospital several days or sometimes weeks after the onset of illness with severe fluid and electrolyte deficits, anemia, sepsis, and malnourishment. Frequently, even the neonates who are delivered in the hospitals are referred late to specialist centers, often not well resuscitated and transported in suboptimal conditions from far locations. These babies are usually hypothermic, septic, and haemo-dynamically unstable and frail on arrival at the referral centres, further compounding the problems. Coupled with inadequate manpower and poor facilities with often lack of neonatal intensive care even at the major tertiary health institutions, the majority of these babies eventually die. Besides, surgical intervention in such babies often leads to high postoperative morbidity and mortality. ${ }^{16}$

By 2030, end preventable deaths of newborns and children under 5 years of age, with all countries aiming to reduce neonatal mortality to at least as low as 12 per 1,000 live births and under-5 mortalities to at least as low as 25 per 1,000 live births. $^{3}$ Bangladesh has a stable, growing economy, but living standards have yet to improve for the poor and vulnerable segments of the population..$^{5}$ This study is done to see the types of neonatal surgical patients admitted in this hospital and their management, outcome with limited facilities and find out the ways to improve the scenario to contribute in achieving SDG 3.

\section{Materials and Methods}

This was a descriptive study with retrospective record review of all admitted neonates done over a period of 17 years from July 2001 to June 2018 and carried out in the Department of Paediatric Surgery of Dhaka Medical College Hospital. A total of 2492 neonates were admitted during this period and it was the $16.16 \%$ of total number of 15414 paediatric surgical admission upto 12 years of age. Parameters of clinical presentations at the time of admission, measures of resuscitation and peri-operative measures were 
taken and recorded. Diagnoses of the patients were based on detailed history, complete physical examination and laboratory and radiological findings. A pre-designed, semi-structured questionnaire was used to collect data. Detail history of each patient was collected and recorded from previous record. Age, sex, date of delivery, mode of delivery, weight during admission, detail history of presenting complaints, history of consanguinity and family history of birth defects were taken. Thorough examination history of baby including abdomen, perineum, head neck region and limbs were recorded. History of resuscitation, types of antibiotics, surgical interventions, morbidity and mortality were also recorded. Statistical assessments were done by SPSS version 22 was obtained from the Ethical Committee of the Dhaka Medical College.

\section{Results}

Total number of neonates admitted during the study period was 2492 surgical problems. The age of the neonates ranged from birth to 28 days with the mean age of $7.9 \pm 4$ days, weight ranged from 1.0 to 3.9 $\mathrm{kg}$. Majority of the patients came from poor and lower middle class socioeconomic condition. Male: female ratio was $3: 2$.

The major clinical presentations of the patients included abdominal distension (29.17\%), bilious vomiting $(22.51 \%$ and failure to pass meconium $(28.0 \%)$ (table I). Some patients exhibited dehydration (8.71\%) and fever (7.78\%), abdominal wall defects (4.29\%), dribbling of urine $(2.97 \%)$ and respiratory distress $(0.88 \%)$.

Table I: Clinical presentations of neonatal surgical patients $(\mathrm{n}=2492)$

\begin{tabular}{lcc}
\hline Presentation & Frequency & $(\%)$ \\
\hline Abdominal distension & 727 & 29.17 \\
Failure to pass meconium & 698 & 28.0 \\
Bilious vomiting & 561 & 22.51 \\
Dehydration & 217 & 8.707 \\
Fever & 194 & 7.78 \\
Dribbling of Urine & 74 & 2.969 \\
Abdominal Wall Defects & 107 & 4.29 \\
Respiratory Distress & 22 & 0.88 \\
\hline
\end{tabular}

The most common variety of neonatal surgical patients was ARM (806). Among these 516 $(64.02 \%)$ patients had high variety and 290 (35.98\%) patients had low variety ARM. This was followed next by Hirschsprung disease, 487 $(19.54 \%)$ of the total cases. Intestinal atresia 246 (09.87\%), omphalocele 163 (06.54\%), meconium ileus $154(06.18 \%)$, volvulous neonatoram 125 (05.02\%), septicemia $114(04.57 \%)$, posterior urethral valve $78(03.13 \%)$, gastroschisis 75 (03.01\%), abscess 57 (02.29\%), congenital diaphragmatic hernia $54 \quad(02.17 \%)$, ectopia vesicae $50(02.01 \%)$, infantile pyloric stenosis 42 $(01.68 \%)$, tracheo-oesophageal fistula 24 $(0.96 \%)$, prune belly syndrome $8(0.32 \%)$, neonatal injury $5(0.20 \%)$, conjoint twin 4 $(0.16 \%)$ were the patients (table II).

Table II: Varity of Neonatal Surgical Patients $(n=2492)$

\begin{tabular}{lll}
\hline Cause & Frequency & $(\%)$ \\
\hline Anorectal malformation & 806 & 32.34 \\
(ARM) & & \\
Hirschsprung's disease & 487 & 19.54 \\
Intestinal atresia & 246 & 09.87 \\
Omphalocele & 163 & 06.54 \\
Meconium ileus & 154 & 06.18 \\
Volvulous neonatoram & 125 & 05.02 \\
Septicemia & 114 & 04.57 \\
Posterior Urethral Valve & 78 & 03.13 \\
Gastroschisis & 75 & 03.01 \\
Abscess & 57 & 02.29 \\
Congenital Diaphragmatic & 54 & 02.17 \\
Hernia & & \\
Ectopia Vesicae & 50 & 02.01 \\
Infantile pyloric stenosis & 42 & 01.68 \\
Tracheo-oesophageal fistula & 24 & 0.96 \\
Prune belly syndrome & 8 & 0.32 \\
Neonatal injury & 5 & 0.20 \\
Conjoint twin & 4 & 0.16 \\
\hline
\end{tabular}

One thousand seven hundred and ninety-one patients (71.86\%) were managed surgically (table III).

Table III: Treatment modalities of the patients $(n=2492)$

\begin{tabular}{|c|c|c|}
\hline Treatment modalities & Frequency & $(\%)$ \\
\hline Conservative & 701 & 28.13 \\
\hline Pelvic colostomy & 541 & 21.71 \\
\hline $\begin{array}{l}\text { Laparotomy, labelling biopsy } \\
\text { and colostomy }\end{array}$ & 376 & 15.09 \\
\hline $\begin{array}{l}\text { Laparotomy, resection and } \\
\text { primary anastomosis }\end{array}$ & 261 & 10.47 \\
\hline Anoplasty & 239 & 9.59 \\
\hline Laparotomy and Repair & 135 & 5.42 \\
\hline Ileostomy & 104 & 4.17 \\
\hline Drainage & 45 & 1.82 \\
\hline Primary Repair & 38 & 1.52 \\
\hline Fulgaration & 28 & 1.12 \\
\hline Cutaneous Vesicostomy & 24 & 0.96 \\
\hline \multirow{2}{*}{\multicolumn{3}{|c|}{$\begin{array}{l}\text { Out of } 2492 \text { patients, wound infection } \\
\text { developed in } 160(6.42 \%) \text { patients and total } 351 \\
\text { died, } 127(5.10 \%) \text { before surgery and } 224(8.99 \\
\%) \text { after surgery (table IV). The mortality rate } \\
\text { was } 14.09 \% \text {. } \\
\text { Table IV: Morbidity and mortality of the patients }(n=2492)\end{array}$}} \\
\hline & & \\
\hline Morbidity and mortality & Frequency & $(\%)$ \\
\hline \multicolumn{3}{|l|}{ After surgical intervention } \\
\hline Wound infection & 160 & 6.42 \\
\hline Death & 224 & 8.99 \\
\hline \multicolumn{3}{|l|}{ After conservative treatment } \\
\hline Death & 127 & 5.10 \\
\hline Total death & 351 & 14.09 \\
\hline
\end{tabular}




\section{Discussion}

The first 28 days of life - the neonatal period - is the most vulnerable time for a child's survival. Children face the highest risk of dying in their first month of life at an average global rate of 18 deaths per 1,000 live births in 2017. Comparatively, the probability of dying after the first month but before reaching age 1 was 12 and after age 1 but before age 5 was 10 . Globally, 2.5 million children died in the first month of life in 2017 alone - approximately 7,000 neonatal deaths every day - most of which occurred in the first week, with about 1 million dying on the first day and close to 1 million dying within the next six days. ${ }^{2}$ A child born in a least developed country is almost 14 times more likely to die during the first 28 days of life than a child born in an industrialized country. And these burdens of death are heavy for Africa and Asia, accounts for 95 per cent maternal and 90 per cent newborn deaths. ${ }^{17}$

Congenital abnormalities accounted for over $82.0 \%$ of all neonatal surgical conditions. This finding was similar to other studies. ${ }^{15,18}$ The most common surgical conditions in the newborn involve the gastrointestinal tract. This finding was similar to other studies. ${ }^{19,20}$ Boys were predominant group in this study, similar finding was noted in other studies. ${ }^{21-23}$

In this study, early presentation was observed among ARM, gastroschisis, omphalocele major and meconium ileus. Early onset of symptom and rapid deterioration of patients' condition in intestinal obstruction and easy approach to diagnosis in ARM was probably the cause of early presentation. On the other hand, presentation was later in Hirschsprung disease, sepsis and malrotation because of variability in onset of symptom and lack of specificity.

In the present study, the commonest congenital abnormalities requiring surgical intervention were anorectal malformations, Hirschsprung disease, small intestinal obstruction, omphalocele and gastroschisis. Similar finding was noted by other studies. ${ }^{15,19}$ Neonatal intestinal obstruction (NIO) was the most common form of neonatal emergencies $1932(77.53 \%)$, similar finding to other studies. ${ }^{24,25}$

Neonatal intestinal obstruction (NIO) was the most common form of neonatal emergencies. It was caused by a group of congenital anomalies and some other acquired conditions. NIO presented with a triad of bile stained vomiting, abdominal distension and failure to pass meconium. The disease process of neonates with surgical problems varies day to day, even start in intrauterine life. In present study, anorectal malformation was the most common presentation among surgical neonates ( $32.34 \%$ of all neonates) and the disease process start just after birth. It was to be showed that late presentation of neonates was a risk factor for surgical outcome. Babies delivered outside the hospital need to travel several hours to get to a specialist hospital that offers neonatal surgical services during which time the baby's condition may detoriate, leading to increased operative risk and mortality. ${ }^{15}$

In this study, various modalities of management were used. Sigmoid colostomy was done for 541 ARM patients. Transverse colostomy and multiple biopsies were done for 376 Hirschsprung disease and rest cases improved by per rectal normal saline irrigation, laxatives. Primary repair was done for gastroschisis, oesophageal atresia and bladder exstrophy. Definitive surgery was done in remaining cases as resection and anastomosis was done for intestinal atresia and midgut volvulus cases.

In case of neonate diaphragm is the only respiratory muscle for respiration, which is abdomino-thoracic. After laparotomy wound closure abdominal movement becomes restricted during reversal and postoperative period due to pain in incision line. In this study, all cases were given pre-emptive analgesia with $0.5-1 \mathrm{ml} / \mathrm{kg}$ local anesthetic (both lignocaine and bupivacaine) in incision line before the incision was made. So for this simple but good pain management technique recovery from anesthesia was good as well as postoperative period was uneventful without any ventilatory support - which this hospital could not provide due to absence of NICU. Thus, this technique helps in reducing mortality. Similar finding was found by Landsman et al.

Total 163 patients with omphalocele were admitted during the study period. 42 patients were treated surgically. Out of them 12 patients were died preoperatively and 16 patients were died postoperatively due to infection, membrane rupture \& other congenital anomalies. 109 patients were managed conservatively with $0.5 \%$ mercurochrome, alcohol, povidone iodine.

Number of patients with posterior urethral valve were 78. Cutaneous vesicostomy was done on 29 patients and catheterizations were done on 16 
patients for temporary relief of symptoms. Fulgaration was done on 33 cases.

Total 54 patients with Congenital Diaphragmatic Hernia were admitted. Out of them 10 patients were died preoperatively during resuscitation. Forty-four neonates were treated surgically and 6 patients were died postoperatively due to unsuccessful recovery from anesthesia \& lack of NICU support. Outcome of other patients were good. Survival rate was $70.37 \%$. The largest multicenter report on $\mathrm{CDH}$ mortality to date is that of the $\mathrm{CDH}$ Study Group, which has reported an overall survival of $68 \%$ which is similar to current study. ${ }^{26,27}$

Seventy-five patients with Gastroschisis were visited as emergency basis \& referred from other centres. Out of them 18 were died preoperatively during resuscitation \& 20 patients were died postoperatively due to inadequate reversal from anesthesia \& lack of NICU support. Total 50 Ectopia Vesicae patients were treated during study period. All of them were treated surgically by primary closure of anterior urinary bladder wall \& anterior abdominal wall. 12 patients were developed postoperative wound dehiscence. Outcome of other neonates were uneventful.

In case of conjoint twin \& esophageal atresia, total 24 patients were treated during study period for esophageal atresia with distal tracheooesophageal fistula. All cases were treated surgically and reversal were good but unfortunately babies were died on postoperative period due to lack of NICU support and septicaemia. One pygopagus twin was successfully separated by multidisciplinary team approach. Department's surgical team on emergency basis also separated 2 conjoint twin from its dead sibling but the baby died two hours after operation in the way for NICU support.

Out of 2492 patients, wound infection developed in $160(6.42 \%)$ patients and total 351 died, 127 $(5.10 \%)$ before surgery and $224(8.99 \%)$ after surgery. The mortality rate was $14.09 \%$. In India, it was $20 \%$ and other authors noted higher mortalities ranging from $30 \%$ to more than $42 \%$. $^{15,28}$

Significantly, more deaths occurred in preterm babies and low birth weight babies. Mortality was higher in preterm babies because of the immaturity of all physiologic functions. Higher mortality was observed in laparotomy for intestinal resection and anastomosis (either for small intestinal obstruction or ruptured NEC), closure of ruptured omphalocele, colostomy, thoracostomy with esophageal anastomosis, and associated with multiple congenital abnormalities, this finding was similar to another study. ${ }^{24}$

Mortality was high among children aged less than a week due to more serious conditions being in this group. Higher mortality was observed in early presenters in this survey probably because most of them were under weight, preterm with multiple associated anomalies and also had high risk types of conditions like gastroschisis, esophageal atresia and intestinal atresia, this was similar to other study. ${ }^{22}$ Presence of associated anomalies was associated with high mortality as reported by other studies. ${ }^{28,29}$

Presentation, diagnosis and treatment modalities of this study are more or less consistent with the other studies. ${ }^{30-32}$ Fluid loss and electrolyte imbalance, metabolic acidosis, hypoglycemia, hypothermia results from inadequate warming during examination and/or negligence, respiratory distress and septicemia are the leading factors for high morbidity and mortality of intestinal obstruction. ${ }^{33}$

Many of these neonates are brought to hospital several days or sometimes weeks after the onset of illness with severe fluid and electrolyte deficits, anemia, sepsis, and malnourishment. Frequently, even the neonates who are delivered in the hospitals are referred late to specialist centres, often not well resuscitated and transported in suboptimal conditions from far locations on bad roads. These babies are usually hypothermic, septic, and hemodynamically unstable and frail on arrival at the referral centers, further compounding the problems Previously mortality was decreased but in the recent year it was increasing, mostly due to more admission occurs in neonatal emergencies.

\section{Conclusion}

In developing countries, the role of paediatric surgeons is multidimensional due to socio-political and economic reasons. Paediatric surgeons by their skill and teamwork greatly improved the neonatal surgical services and contributing significantly in reducing infant as well as neonatal mortality rate and thus help in achieving SDG3. But to improve further NICU and other support systems are very essential. It is advisable that UNICEF and WHO should include paediatric surgery in their activities including training and infrastructure development especially in developing countries to design the future for the children. 
Conflict of interest: None

Funding: None

Submitted: $14^{\text {th }}$ November, 2019

Final revision received: $25^{\text {th }}$ February, 2020

Accepted: $19^{\text {th }}$ March, 2020

Published online: $1^{\text {st }}$ April, 2020

\section{References}

1. Black RE, Morris SS, Bryce J. Where and why are 10 million children dying every year?. The Lancet 2003; 361: 2226-34.

2. Alkema L, Chou D, Hogan D, Zhang S, et al. Global, regional, and national levels and trends in maternal mortality between 1990 and 2015, with scenariobased projections to 2030: a systematic analysis by the UN Maternal Mortality Estimation Inter-Agency Group. The Lancet. 2016; 387: 462-74.

3. United Nations.2001. General Assembly, 56th session. Road map towards the implementation of the United Nations millennium declaration: report of the Secretary-General (UN document no. A/56/326). New York: United Nations.2001. url: research.un.org/en/docs/dev/2000-2015

4. Lawn JE, Cousens S, Zupan J: Lancet Neonatal Survival Steering Team. 4 million neonatal deaths: when? Where? Why? The Lancet 2005; 365: 891-900.

5. World Health Organization. Birth defects 2009.2009.

url:apps.who.int/gb/ebwha/pdf_files/EB126/B126 10-en.pdf

6. Tanteles GA, Suri M. Classification and etiology of birth defects. Pediatr Child Health 2007; 17: 233-43.

7. United Nations. World Population Prospects 2019.2019

url:population.un.org/wpp/Publications/Files/WPP 2019 Highlights.pdf

8. World Health Organization. Mortality Country Fact Sheet 2006: World Health Statistics 2006. url: www.who.int/whosis/whostat2006.pdf

9. Ravitch MM, O'Neill JA and Rowe MI. Jejunoileal atresia. In Paediatric Surgery (O’Neill JA, Rowe MI, Grosfeld JL, Fonkalsrud EW and Coran AG eds.). 1998; 5: 1145-58.

10. Murphree SH and Dunkley AS. Colon atresia and stenosis in Zimbabwe: Case reports and a review of the literature. Cent Afr J Med 1992; 38: 463-65.

11. Hanif A, Hassan K, Hasina K et al. Neonatal Intestinal Obstruction: Six years experience in Dhaka Medical College Hospital, Bangladesh. BJMS 2009; 15: 42-45.

12. Gattett L, Jeffrey K, Michael M. Use of MRI and UUS in the antenatal diagnosis of placenta accrete. J Soc Gynecol Invest 2002; 9: 37-40.
13. Rowe MI. The newborn as a surgical patient. In: O'Nell JA, Rowe MI, Grosfeld JL, Fonkalsrud EW, Coran AG Ed. Pediatric Surgery. 1998; 5: 43-55.

14. Blyth B, Snyder HM, Duckett JW. Antenatal diagnosis and subsequent management of hydronephrosis. J Urol 1993; 149: 693-98.

15. Seth A, Chanchlani R, Rakhonde AK. Neonatal gastrointestinal emergencies in a tertiary care center in Bhopal, India: A prospective study. IJSS Journal of Surgery 2015; 1: 1-4.

16. Chirdan LB, Ngiloi PJ, Elhalaby EA. Neonatal surgery in Africa. J sem pedi surg 2012;21:151-59.

17. Ameh EA, Nmadu PT. Intestinal Volvulus: Aetiology, Morbidity, and Mortality in Nigerian Children. Pediatr Surg Int 2000; 16: 50-2.

18. Nwomeh BC, Mshelbwala PM. Pediatric surgical specialty: How relevant to Africa? Afr J Paediatr Surg 2004; 1: 36-42.

19. Osifo OD, Ovueni ME. The prevalence, patterns, and causes of deaths of surgical neonates at two African referral pediatric surgical centers. Ann Pediatr Surg 2009; 5: 194-99.

20. White RD. Surgical emergencies in: Roberts KB, editor. Manual of clinical problems in paediatrics. Lippincott Williams and Wilkins Publishers 2000; 5: $275-81$

21. Wella HL, Farahat SMM. Patterns and management outcomes of neonatal acute surgical conditions in Alexandria, Egypt. East Cent Afr J Surg 2015; 20: 69-79.

22. Sharif M, Abood H, Elsiddig IE, Atwan F. Pattern and outcome of neonatal surgery: Experience at King Fahad Hospital Al-Baha. Pakistan J Med Health Sci 2014; 8: 262-67.

23. Ilori IU, Ituen AM, Eyo CS. Factors associated with mortality in neonatal surgical emergencies in a developing tertiary hospital in Nigeria. Open $\mathrm{J}$ Paediatr 2013; 3: 231-35.

24. Sowande OA, Ogundoyin OO, Adejuyigbe O. Pattern and factors affecting management outcome of neonatal emergency surgery in Ile-Ife, Nigeria. Surg Pract 2007; 11: 71-75.

25. Adejuyigbe O, Jeje EA, Owa J, Adeoba EA. Neonatal intestinal obstruction in Ile Ife, Nigeria. Niger Med J 1992; 22: 24-28.

26. Rahman SM, Talukder SA, Hanif A et al. Management of Omphalocele with Limited Facilities. J Dhaka Med coll 2004; 13: 58-62.

27. Bagolan $P$, Casaccia G, Crescenzi F, et al. Impact of a current treatment protocol on outcome of high-risk congenital diaphragmatic hernia. J Pediatr Surg 2004; 39:313-18.

28. Cantre D, Lopes MF, Madriga A, Oliveiros B, Viana JS, Cabrita AS et al. Early mortality after neonatal surgery: analysis of risk factors in an optimized health care system for the surgical newborn. Rev Bras Epidemiol 2013; 16: 943-52. 
29. Manchanda V, Sarin YK, Ramji S. Prognostic factors determining mortality in surgical neonates. J Neonatal Surg 2012; 1: 3-9.

30. Welch GH, Azmy AF and Ziervogel MA. The surgery of malrotation and midgut volvulus: A nine-year experience in neonates. Ann R Coll Surg Engl 1983; 65: 244-47.

31. Nixon HH. Congenital abnormalities of gut. Br J Hosp Med 1977; 11: 202-19.
32. Robertson J, Azmy AF and Young DG. Surgery in necrotizing enterocolities. Br J Surg 1987; 4: 387-89.

33. Landsman IS, Vustar M and Hays SR. Pediatric anesthesia. In Pediatric Surgery (O'Neill JA, Rowe MI, Grosfeld JL, Fonkalsrud EW and Coran AG eds.). 2006; 6: 221-56. 